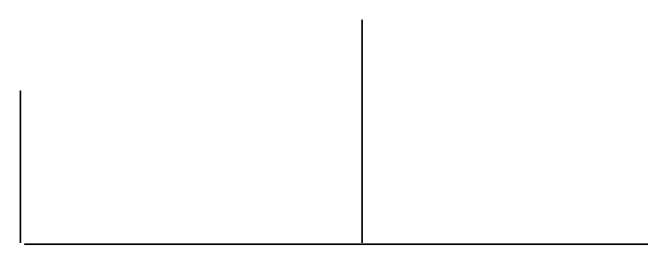

Rev. Latinoam. Psicopat. Fund., VI, 2, 114-125

\title{
As inscrições de um corpo - considerações sobre uma Oficina de Escrita com toxicômanos num centro de recuperação*
}

Iza Maria Abadi de Oliveira

\begin{abstract}
Este estudo apresenta reflexões acerca de uma intervenção clínica no campo das toxicomanias, realizada a partir de uma Oficina de Escrita com pacientes internos num Centro de Recuperação para Alcoolistas e Drogados. Mediante a análise de dois textos produzidos na Oficina, examinaremos as toxicomanias como um lugar discursivo que evoca os conflitos de uma cultura. Também discutiremos a construção de narrativas como uma forma de representação de uma determinada condição subjetiva. A escrita assume um estatuto clínico à medida que possibilita uma inscrição subjetiva, constituindo-se num registro de um outro corpo, composto por recortes pulsionais. Essa abordagem é sustentada por referências bibliográficas da psicanálise freudiano-lacaniana.
\end{abstract}

Palavras-chave: Toxicomanias, escrita, corpo, imaginário

* Este trabalho recebeu a primeira menção honrosa do Concurso Pierre Fédida de Ensaios Inéditos de Psicopatologia Fundamental - /2002. 


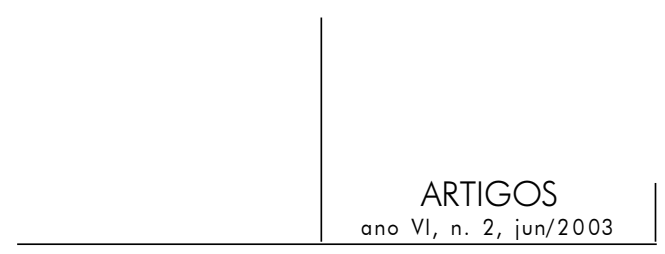

À Lucy Fontoura pelo testemunho de um tempo

Introdução

Esta experiência surgiu, primeiramente, por um pedido da instituição para a realização de um trabalho com grupos, juntamente com o trabalho individual que vinha sendo realizado. Diante dessa demanda, uma primeira questão se colocou: como fazer isso sem instrumentalizar com técnicas convencionalizadas de intervenção em grupo, como, por exemplo, as dinâmicas de grupos? A oficina de escrita se apresentou como essa outra forma e, também, uma possibilidade de extensão dos materiais escritos que apareciam nos atendimentos individuais, pois muitos pacientes traziam seus textos para lerem durante as sessões. Diante disso, a criação de um espaço onde esse ato de escritura pudesse circular, ser compartilhado e reconhecido, se configurou numa demanda legítima.

Trata-se de uma intervenção clínica não somente porque estão presentes dispositivos clínicos como a transferência, um lugar de enunciação, de alteridade, mas, principalmente, porque é uma experiência conduzida pela ética da psicanálise. Ou seja, uma intervenção em que, por meio da produção de narrativas, os sujeitos em sofrimento psíquico encontrassem uma forma de elaborar uma resposta ética para seu conflito psíquico, não como uma maneira de solucioná-lo, mas de, ao menos, suportá-lo. Nas suas escrituras (carta, poema, conto etc.), que encontrassem um lugar onde ocorresse um ato mobilizador de seu desejo, uma vez que estes sujeitos quase perderam essa condição subjetiva, entregando-se completamente ao gozo da droga.

\section{As toxicomanias e as produções imaginárias}

A concepção de toxicomania que estamos trabalhando se sustenta nas elaborações apresentadas por Melman (1992 e 1997), Calligaris (1996), Conte (1996) e Ribeiro (1997). Eles consideram a toxicomania não uma estrutura clínica, mas uma posição discursiva produzida por uma determinada lógica organizadora de uma cultura. Dessa forma, a toxicomania é uma resposta imaginária à lógica da economia de mercado predominante em nossos tempos, que coloca o consumidor como dependente do objeto e goza com ele. Por intermédio do objeto-droga, o toxicômano se inscreve nessa lógica, buscando 


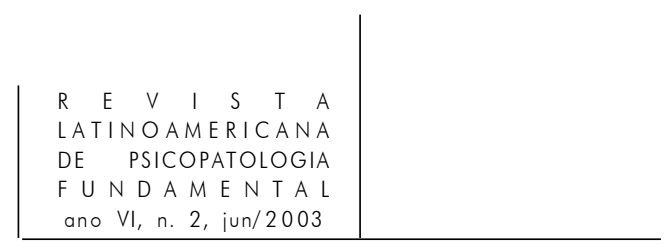

suprimir a falta constitutiva da condição humana, e isso se configura uma modalidade discursiva. Por isso, Melman considera a toxicomania um sintoma social, uma vez que é um discurso dominante de nossos tempos. Nossa cultura, cada vez mais produz respostas imaginárias ao mal-estar, tanto que Maria Rita Khel, em seu livro Ética e psicanálise (2002), aponta que as formações imaginárias representam o "espaço púbico" no mundo atual, onde qualquer forma de alteridade se torna ameaçadora, pois essas formações "organizam-se em torno do $e u$ narcísico, das identificações e das demandas de amor e reconhecimento" (p. 25).

No entendimento de Ribeiro (1997), é diferente a significação da droga no campo científico e nas relações cotidianas. Nesta última, não há um saber objetivo, pois é um significante carregado de representações sociais construídas; “... nesse sentido, não seria demais afirmar que os usuários de droga consomem, não produtos químicos, mas produtos imaginários. E, como sabemos, o imaginário sempre nos engana" (p. 28). Com isso, Ribeiro indica que as toxicomanias são formas de predomínio das formações imaginárias em nossos tempos. Entre os produtos imaginários consumidos pelos toxicômanos está o imperativo do gozo, que suprime todo e qualquer mal-estar. Estes sujeitos presenciam e revelam os enigmas da promessa moderna e seus dejetos.

Sabemos que a alienação imaginária, a relação de especularidade, é constituinte do sujeito. O olhar funciona, para a criança, como um espelho em que ela se vê e se reconhece, constituindo sua primeira imagem, que se compõe antes mesmo de ter um domínio real de seu corpo. Desta relação especular depende sua primeira realidade, que é virtual. A psicanalista Ana Costa, em seu livro A ficção do si mesmo (1998), observa que nesse momento o corpo do sujeito passa a ser a imagem do corpo do outro. Esse processo não se refere somente ao desenvolvimento psíquico, mas à problemática constitutiva do sujeito.

As toxicomanias podem ser consideradas como o retorno deste momento de entrega absoluta ao Outro. Tempo do fascínio e da efemeridade. A alienação produz, juntamente com o retorno de uma posição infantil de objeto do desejo, atos sem pensamento à medida que não há permanência de suas referências; por isso, também, a alienação imaginária não constitui uma identificação simbólica para o sujeito. Como aponta Ana Costa, “... a imagem não cumpre o que promete, na medida em que carrega junto o engano da promessa e o fracasso da plenitude" (Ibid., p. 52).

As toxicomanias, como efeito do predomínio das formações imaginárias, revelam o retorno do momento de passividade, onde o desejo está alienado do lado do Outro; o toxicômano entrega-se vorazmente aos mandatos que vêm desse lugar, numa condição alienante. Quando o toxicômano se diz dominado pela droga, encontramos uma posição de alienação, de entrega absoluta a este Outro. Quando 


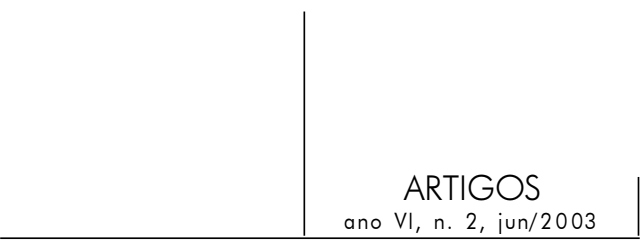

essa relação fracassa, o trabalho é reconstituir esse Outro, não como o lugar da droga, mas de um referente que dê sustentação simbólica a este sujeito.

Marta Conte (2002) demonstra os momentos do tempo lógico formulado por Lacan - o instante de ver, tempo de compreender e momento de concluir no tratamento das toxicomanias. Ela aponta que o instante de ver é o momento em que o toxicômano não se vê, pois "perdeu o brilho do olhar do Outro, e conseqüentemente sua auto-imagem" (p. 34). O trabalho, num primeiro momento, é reconstituir essa função especular para que o paciente organize seu olhar.

\section{A escrita de um corpo}

A Oficina de Escrita funcionou por um período de cinco meses, com encontros quinzenais, com duração de três horas. A grande parte desses encontros era sustentada, primeiramente, por algum material literário, quase sempre um conto. Após discussão sobre o texto, uma vez instigados por alguma questão, se produzia um escrito que representava o efeito deste trabalho. Isso não era uma obrigatoriedade, mas uma contingência. Também, tinha-se liberdade de trazer o que se escrevia fora dessa atividade. A seguir, apresentaremos dois dos textos produzidos na Oficina. O primeiro se refere à escolha do nome da Oficina, feita pelo grupo, enquanto o segundo texto, intitulado Considerações de um almoxarife, instiga questões sobre o lugar destes sujeitos na cultura.

\section{O círculo da roda}

A história começa quando na juventude de um dos pacientes se reunia com amigos e amigas, na sexta-feira, à noite, para fumar maconha. O baseado passava de mão em mão, formando uma roda. Nessa roda, escutava-se som e rolavam diversos assuntos. Quando terminava um baseado, acendia-se outro e novamente se formava a roda até a madrugada do outro dia.

Depois, com o tempo, os mesmos amigos se encontravam para cheirar cocaína e beber vodka com fanta, bebida preferida da época, e sempre formando a roda para cheirar... Todos os amigos estavam no auge da juventude, e nunca pensaram que um dia isso teria conseqüências em suas vidas. Um deles, com idade não mais de jovem, se encontra numa clínica para tratamento de alcoolismo e dependência química. Nessa clínica termina a roda e começa o círculo.

Conhecendo pessoas de todas as classes sociais, e cada um com problemas diferentes, vindo a formar um círculo, porque na realidade todos têm o mesmo 


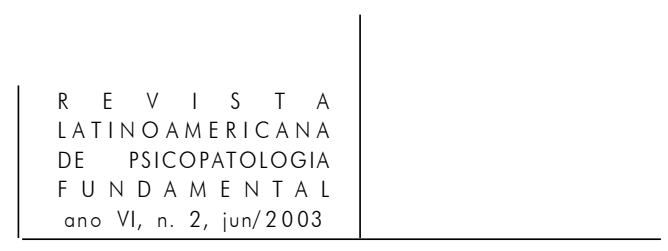

objetivo: parar com o mal que aflige a si próprio e a outras pessoas que estão ao seu redor. Afinal, todos são dependentes, com um só objetivo: sair da clínica com o corpo limpo, e com a graça de Deus, ter uma vida normal, longe do alcoolismo e da droga.

P.N.A.C.

Este nome "O círculo da roda" sugere considerações no que se refere às especificidades da toxicomania, precisamente sobre a proximidade destes dois termos: círculo e roda. Ambos se formam a partir de um ponto: o círculo é a delimitação geográfica feita por uma circunferência, enquanto a roda é um instrumento que se movimenta ao redor de um eixo.

$\mathrm{O}$ que move esse grupo, num primeiro momento, é a droga, "o baseado rolava de mão em mão, formando uma roda”, escreve ele. Observamos que, neste movimento, há momentos de descontinuidade que ocorrem quando termina a droga, e "logo acende outro".

O elo de ligação muda com o tempo: do baseado para a cocaína e a bebida alcoólica. Aqui, também podemos fazer referência ao banquete totêmico, como um momento em que, por meio da incorporação de um objeto, se funda um grupo. Fumar, beber, cheirar, são movimentos ligados ao corpo; não por acaso, esses pacientes, quando se referem à cura, denominam-na de um estado de "corpo limpo". A toxicomania é um processo de incorporação de um objeto carregado de atributos significantes, legitimado pelo grupo.

"Nessa clínica termina a roda e começa o círculo", este enunciado indica que outro elemento de ligação se coloca nesta instituição. Talvez ainda a droga, não mais de forma positivada. Neste lugar, ainda o significante droga está muito erotizado, tanto que as conversas giram em torno do tempo de uso, como faziam, o que acontecia etc. Ao mesmo tempo que é uma forma de elaborar esse tempo perdido, também sabemos da importância de esvaziamento desse lugar. Talvez por isso o significante Deus surja como substituto desse lugar da droga, como potência e elemento de união.

O trabalho clínico consiste em provocar um deslocamento do significante droga, como o eixo que movimenta a vida desses sujeitos. "O círculo da roda" sugere que o lugar que o sujeito ocupa se organiza a partir de um ponto onde ele pode se referenciar. É desse lugar que ele fala e que é falado. A Fábula do Lobo e do Cordeiro é ilustrativa disso. Após o cordeiro correr muito do lobo, para que este não the comesse, ele sobe numa torre de igreja e de lá começa a zombar do lobo, dizendo-lhe: "Aqui você não me pega, aqui você não me pega, ah, ah, ah!". Então o lobo fala: "Não és tu que fala, é o teu lugar!".

O lugar produz posições discursivas. Porém, para que ocorra um deslocamento de lugares, é necessária uma relação de alteridade, de diferença de posi- 


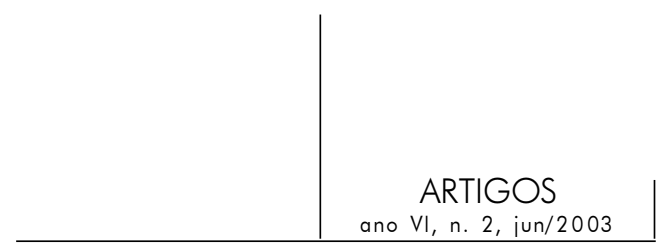

ções. Para acontecer uma ruptura nesta roda, onde todos fumam, cheiram, escutam as mesmas músicas, etc., é imprescindível a emergência de um elemento de diferença e, portanto, de mal-estar. A procura pela clínica indica que algo fracassou nessa roda, mesmo que se busque, novamente, um círculo. Isso é inevitável, uma vez que todos nós nos movimentamos a partir de alguma posição referencial.

\section{Considerações de um almoxarife}

Enxadas, enxadões, enxadinhas; limas, formões, martelos e pregos; canos, baldes, pás e rastéis; etc. Pois este é o ambiente do local onde ora escrevo. $O$ almoxarifado dessa clínica que também tem, claro, canetas, lápis, rádio AM/FM, máquina de escrever, cafezinho e idéias. E-imprescindível-tem dois mascotes: um rato e uma pererequinha (que anda sumida nos últimos dias, não sei o que houve com ela). E - como haveria de esquecer - tem a mãozinha, uma alusão à Família Adams, pena ser de madeira, mas está ali, digna do cenário: um porão úmido, adornado com teias de aranha que contrastam com a limpeza da escrivaninha e com a brancura dos papéis espalhados sobre ela. $O$ aroma do ambiente não é de enxofre, mas é esquisito e traz uma sutil provocação ao imaginário. $O$ rato e a pererequinha ainda não têm nome; as aranhas, formigas e mariposas, têm aparições apenas ocasionais no cenário.

A rotina do porão tem dois momentos perfeitamente identificáveis e um terceiro absolutamente imprevisível. O primeiro momento identificável, subdividese em começo e término do expediente, quando há o movimento de internos na busca e devolução de ferramentas, o segundo momento identificável é o período intermediário dos expedientes matutinos e vespertinos quando a presença dos internos no porão não foge a duas respostas: socorrem-se de alguma ferramenta para dar continuidade às suas tarefas ou simplesmente para "dar um tempo" em suas atividades. E o terceiro momento, imprevisível, é o mais atraente, uma vez que não escolhe hora e invariavelmente vem acompanhado do "Será que vai dar certo?". Certa vez, criativos e habilidosos internos concentravam as suas atenções na feitura de uma patrola de madeira a fim de presentear o pastor que administrava o Centro. A escolha do presente derivava do contentamento demonstrado pelo pastor dias antes da Páscoa, com a vinda do maquinário da prefeitura para fazer melhorias no local. Havia um bom tempo que estavam requisitadas $e$, finalmente, as patrolas chegavam para fazer o trabalho. No dia da Páscoa, o pastor recebeu de bom grado o reconhecimento de sua dedicação pelos internos. O rato e a pererequinha já estão me olhando de um jeito meio 


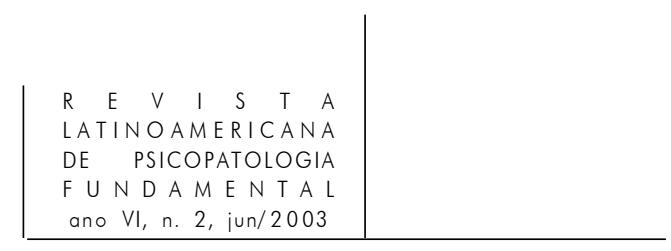

desconfiado. Tá bom, vou mudar o rumo da prosa, uma vez que este texto não é para puxar o saco de ninguém e sim mostrar o que se passa aqui, no porão, neste início de outono.

De outra feita, a pererequinha mostrou que não está aqui só para enfeite, ou fazer número. Ela tem serventia. E uma de suas atribuições é evitar que as pessoas congestionem a entrada do porão. Era costume chegarem aqui e deixarem o corpo para o lado de fora e apenas estenderem o pescoço para falar com o almoxarife, que fica do lado de dentro. Para acabar com a situação, a pererequinha não se fez de rogada e escolheu a esposa do pastor para pregarlhe um delicioso susto. Enquanto a jovem senhora conversava com o almoxarife na posição antes descrita, a mascotezinha saltou em suas pernas, causando constrangimento, mas resolvendo a questão.

O porão, mesmo situado na parte inferior da casa, está localizado num ponto estratégico no Centro de Reabilitação, uma vez que aqui é possível observar... (Não tem jeito. O Marcelo - um menino de três anos, filho do casal que interinamente administra o Centro - não me deixa continuar o relato. A tudo o que vê faz perguntas. Ficou indignado com o número de lâmpadas (três), "lá em casa só precisa uma luz na sala!”, compara. E não pára. Pergunta se eu durmo aqui; se é aquele "choque" que liga a luz? É. Ganha um bombom. Quer dois. Não leva. Aí deduz: "É para mim não ficar gordo, né tio." Depois de uma saraivada de perguntas, Marcelo percebe que não lhe dou muita atenção, uma vez que prossigo escrevendo, e sai).

Mas, como eu ia dizendo, daqui é possível se observar o movimento dos internos no pátio; o entra-e-sai de carros; o vento que sacode as folhas das árvores e da videira que se alastra ao lado da janela, quando faz sol ou enfeita o tempo; os ruídos do dia; enfim.

Porão. Sempre que se fala em porão, inúmeras imagens povoam nossa mente. Não é por acaso. O escritor Allan Poe se deliciava produzindo tramas macabras, tendo o porão como cenário. Geralmente, tudo o que recebe o destino de porão não tem serventia para o momento. Mas pode voltar a qualquer hora, vivo. O sótão também é um lugar marginal de qualquer casa. Mas é diferente. Em muitas residências, o espaço é usado como ateliês ou para mobilizar românticas alcovas. Já o porão não se presta a estes requintes. Ele instiga a situações mais compactas, rudes. É mais fácil criar situações dantescas, pesadas, que as que transpirem leveza, suavidade. Mas, como nada é impossivel, é mais do que provável que estamos num porão atípico.

O porão, apresentado no texto, serve como metáfora do lugar da toxicomania na cultura. Uma clínica de recuperação pode ser pensada como um 


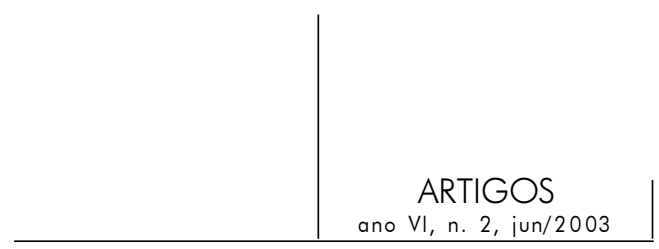

lugar onde são depositados os dejetos de uma cultura. A referência de Marta Conte (1996), de que as toxicomanias estão na contramão do discurso dominante de nossa cultura, pressupõe que elas não estão fora, mas ocupam um lugar marginal.

Gaston de Bachelard, em uma das suas obras mais importantes dedicadas ao estudo da imaginação poética e criadora, A poética do espaço (1978 [1957]), se refere a casa como um espaço de intimidade, um lugar de representação, onde se produz a memória e a imaginação: “... a casa é um corpo de imagens que dão ao homem razões ou ilusões de estabilidade" (p. 208). O porão, para ele, é o "ser obscuro da casa", onde se localiza a "loucura enterrada, dramas murados", é o "espaço íntimo das intrigas subterrâneas".

Assim como o porão de Bachelard, a toxicomania é esse lugar discursivo que engendra os conflitos de uma cultura. O discurso desses sujeitos revela os dramas de nossa modernidade. A escuridão desse lugar é o assujeitamento ao objeto-droga. Na clínica, encontramos dramas murados. Muitos pacientes se referem à clínica como "dentro" e a outros espaços como "fora". Muitos dizem: "Meu medo é quando eu sair lá fora, aqui dentro, estou bem". A Banda de Moebius demonstra que não há limites entre o dentro e o fora. Pode acontecer que, dependendo da posição daquele que olha, se tenha representações do que seja o dentro e o fora, porém são percepções imaginárias. Assim, o porão não está fora da casa, ele ocupa um lugar marginal e, como tudo o que está à margem, produz tensão. Por isso, podemos considerar a toxicomania como um discurso testemunho dos conflitos que engendram nossa cultura moderna.

A experiência na Oficina de Escrita serviu como uma forma de vazão destas vozes naufragadas pelos ideais que desnorteiam nossos tempos, possibilitando romper as fronteiras dessa dor privada. Isto porque o ato de escrita coloca em cena não somente uma descrição, mas um momento de inscrição subjetiva, podendo assumir o caráter de estatuto clínico, pois, diferentemente do imaginário, ela não dispensa o pensamento.

A partir desta experiência, encontramos dois pontos de interseção e de tensão entre o campo da escrita e o da toxicomania: o primeiro se refere ao reconhecimento, enquanto o segundo, à problemática da falta.

Sobre o reconhecimento, constatamos que, no momento de extrema fragilidade psíquica em que os sujeitos se encontram, um ato mínimo pode auxiliar na recuperação de um lugar subjetivo; escrever poderá representar um momento de vazão e organização deste não-lugar, ou dos conflitos deste lugar. Se o toxicômano tornou-se escravo de seu objeto - a droga -, constituindo uma relação em que passou a ser comandado, num total imediatismo, por seu instrumento, algo de um lugar desejante padeceu. $\mathrm{Na}$ dialética do consumo que consome, que consome quem consume, o toxicômano se perdeu. Uma das vertentes deste duelo é a de 


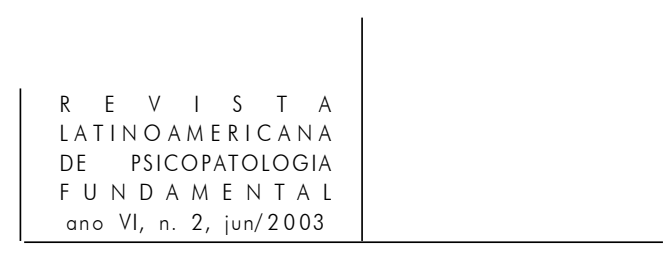

que a droga consumiu o lugar subjetivo do toxicômano. Num Centro de Recuperação, um dos trabalhos é a recuperação deste lugar de desejo, de posição desejante.

O trabalho de produção escrita, para além do conteúdo, da articulação gramatical, da grafia, etc., representa, neste lugar e tempo, um momento de inscrição subjetiva, uma possibilidade de advir, no traço que aí se coloca, um estilo. ${ }^{1}$ O momento de produção e socialização destes escritos é, também, uma forma de elaboração de um tempo e um lugar desse sujeito.

Ana Costa, em Corpo e escrita (2001), indica que a escrita é um suporte corporal que recorta os restos não assimiláveis, o que ela chama de detritos. A escrita também reúne dois objetos pulsionais privilegiados, o olhar e a voz. Segundo ela, a dimensão corporal só se sustenta pelo recorte desses objetos.

A escrita transporta detritos. Eles são o resto de uma operação de separação nunca concluída. Os detritos escapam nesses objetos pulsionais que nos ligam ao Outro. É por isso que eles podem se depositar nos absolutos: nas margens mais execradas da civilização, ou nas construções mais sublimes da mesma. (Costa, 2001, p. 133)

A partir das elaborações dessa autora, consideramos os textos produzidos por estes pacientes como formas de construírem um registro fora deste corpo gozante. Seus textos são este outro corpo, produzido por recortes dos objetos pulsionais. Sabemos que um dos trabalhos com estes sujeitos é operar pela via da parcialidade das pulsões.

As considerações de Ana Costa nos interrogam, também, sobre quais seriam os detritos que carregam os escritos dos sujeitos toxicômanos. Certamente são muitos! Porém, constatamos que eles revelam o grande cenário moderno de que todos nós, sem exceção, fazemos parte: a fragilidade para suportar o mal-estar que nos humaniza. Os toxicômanos demonstram a inconformidade com nosso destino de sujeitos não-completos, sujeitos sexuados, ao mesmo tempo, eles permitem a confrontação com a face escura do desejo. Por isso, Melman considera os toxicômanos como heróis trágicos, pois eles vão até o fim de seus desejos, mesmo que este fim seja a morte:

... o toxicômano nos observa, nos olha, nos vê como pessoas temerosas, que são os pequenos burgueses dementes, que não temos coragem de nosso desejo, preferimos nosso conforto, nosso bem-estar, nosso trabalho, nossa família etc. Quer dizer que o toxicômano nos olha com um pouco de consideração. E é verdade que tratar de heróis é muito difícil. E a gente pode mesmo, por vezes, se sentir culpado por isso. É verdade. Esta é mais uma dificuldade. (1997, p. 33)

1. O psicanalista Edson de Sousa, em um artigo "O inconsciente entre o escrito e o escritor" (1998), escreve sobre o estilo como aquilo que se produz no ato da escrita. 


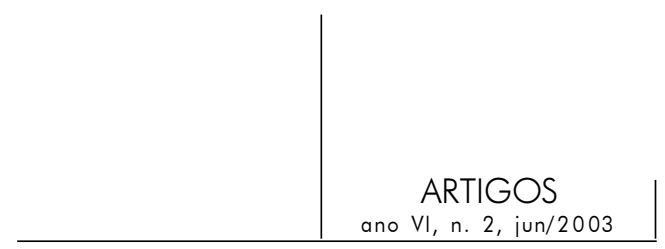

A escrita, como uma metáfora de um corpo que se constitui por recortes, suscita o encontro com a falta. Afinal, as palavras são significantes e não signos; no campo humano, não há uma relação sígnica com as palavras, em que haveria uma correspondência direta da palavra com o sentido. Nos comunicamos numa via significante onde as palavras sempre remetem a novas significações.

Marta Conte (2002) observa que os toxicômanos tentam fundar um outro corpo, por meio das marcas deixadas pela operação de farmakon ${ }^{2}$ (abscessos, cicatrizes, etc.). Podemos considerar essas marcas como detritos de uma inscrição que falhou: a do "brilho do olhar do Outro". A escrita pode servir como registro da reconstrução desse olhar.

\section{Conclusão}

Como vimos, na nossa cultura as formações imaginárias são predominantes, produzindo sujeitos alienados que dispensam o pensamento e a construção de uma significação para a sua condição subjetiva, para o seu conflito psíquico. Diante disso, a Oficina de Escrita se apresentou como uma forma de construção de narrativas que elaborassem algum sentido para o lugar desses sujeitos. Assim, as maneiras de contar, de procurar dar significações aos atos, são formas de construirmos um lugar num espaço e tempo. Isso não é algo natural, é uma construção que se coloca desde que os humanos se movimentam no mundo da linguagem. As narrativas são formas organizadoras da experiência humana e, em cada tempo, apresentam especificidades próprias. Se a toxicomania pode ser pensada como um ato de alienação, uma vez que não produz pensamento e sentido, a escrita é uma forma de construção de uma significação para essa experiência em que um sujeito fala, e não uma droga! Se vivemos um momento em que não há um sentido a priori que legitime as experiências do sujeito, é necessário criar lugares onde se construam sentidos para os atos. Para isso, é imprescindível romper as fronteiras da instância íntima, entendendo que o conflito que ali opera nada mais é do que produto e representante dos conflitos de uma cultura.

2. Conceito formulado por Le Poulichet que se refere à transformação da droga em tóxico, assumindo uma determinada significação para a vida psíquica do sujeito; um suporte de defesa de algo que falhou no processo constituinte do sujeito. 


\section{Referências}

Bachelard, G. A poética do espaço. In: Os pensadores. São Paulo: Abril Cultural, 1978.

CAlligaris, C. Crônicas do individualismo cotidiano. São Paulo: Ática, 1996.

ConTE, M. A clínica institucional com toxicômanos: uma perspectiva psicanalítica. In.: Revista Latinoamericana de Psicopatologia Fundamental, São Paulo, v. II, n. 2, p. 28-43, jun./2002.

Toxicomania: transformação dos ideais sociais em imperativo de consumo. Correio da Associação Psicanalítica de Porto Alegre (APPOA), n. 40, outubro de 1996.

Costa, A. Corpo e escrita: as relações entre memória e transmissão da experiência. Rio de Janeiro: Relume Dumará, 2001.

A ficção do si mesmo: interpretação e ato em psicanálise. Rio de Janeiro: Companhia de Freud, 1998.

Kent, M. R. Sobre ética e psicanálise. São Paulo: Companhia das Letras, 2002.

Melman, C. Alcoolismo, delinqüencia e toxicomania - uma outra forma de gozar. São Paulo: Escuta, 1992.

Entrevista com o psicanalista Charles Melman realizado pelo Cartel de Estudos sobre Toxicomania e Alcoolismo. Correio da Associação Psicanalítica de Porto Alegre (APPOA), ano VI, n. 44, p. 31-4, março de 1997.

124 Ribeiro, E. M. A genealogia de um engano. In: Correio da APPOA - Toxicomanias, Porto Alegre, ano VI, n. 49, agosto de 1997, p. 27-29.

Sousa, E. de. O inconsciente entre o escrito e o escritor. In: Revista da Associação Psicanalítica de Porto Alegre - Psicanálise e literatura. Ano VIII, n. 15, novembro de 1998, p. 28-35.

\section{Resumos}

Este estudio presenta reflexiones acerca de una intervención clínica en el campo de las toxicomanías, realizada a partir de un Taller Literario (Oficina de Escrita) con pacientes internados en un centro de recuperación de alcoholismo y drogadicción. Mediante el análisis de dos textos producidos en la oficina, examinaremos las toxicomanías como un lugar discursivo que evoca los conflictos de una cultura. También discutiremos la construcción de narrativas como una forma de representación de una determinada condición subjetiva. El escribir asume un estatuto clínico en la medida que posibilita una inscripción subjetiva, constituyéndose en un registro de un otro cuerpo, compuesto por recortes pulsionales. Este abordaje es sustentado por referencias bibliográficas del psicoanálisis lacaniano.

Palabras clave: Toxicomanías, escritura, cuerpo, imaginario 


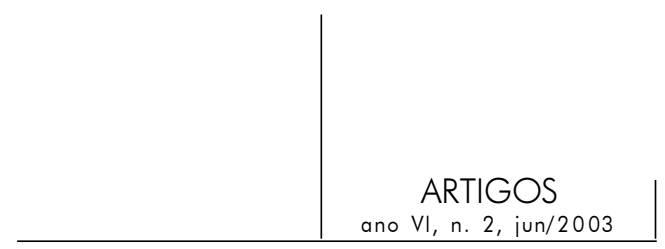

Cet étude présente des réflexions sur l'intervention clinique dans le domaine des toxicomanies à partir d'un Atelier d'Écriture avec des patients internés dans un Centre de Récupération pour Alcoolques et Drogués. A partir de deux textes produits dans l'Atelier, nous examinerons les toxicomanies comme un lieu du discours qui évoque les conflits d'une culture. Nous discuterons, aussi, la construction de narratives en tant que formes de représentation d'une condition subjective donnée. L'écriture assume un statut clinique dans la mesure où elle rend possible une inscription subjective, devenant ainsi un registre d'un autre corps, composé de coupures pulsionnelles. Cet abordage se base sur des références bibliographiques de la psychanalyse freudo-lacanienne.

Mots clés: Toxicomanies, écriture, corps, imaginaire

This study presents reflections about clinical intervention in the area of drug addiction consisting of a writing workshop with patients living at a recovery center for alcoholics and drug addicts. Through the analysis of two texts produced during the workshop, we examine chemical dependence as a place of discourse which evokes the conflicts of a culture. We also discuss the construction of narrative as a form of representing a given subjective condition. Writing takes on a clinical status to the extent that it enables subjective inscription, consisting of the registration of another body, comprised of fragments of drives. This approach is sustained by bibliographical references to Freudian-Lacanian psychoanalysis.

Key words: Drug addiction, writing, body, imagination

Versão inicial recebida em abril de 2002

Aprovado para publicação em abril de 2003 